\title{
BMJ Open Use and abuse of medication during 2014 FIFA World Cup Brazil: a retrospective survey
}

\author{
Martin Vaso, ${ }^{1,2}$ Alexis Weber, ${ }^{1}$ Philippe M Tscholl, ${ }^{3,4}$ Astrid Junge, ${ }^{3,5}$ \\ Jiri Dvorak ${ }^{1,3,6}$
}

To cite: Vaso M, Weber A, Tscholl PM, et al. Use and abuse of medication during 2014 FIFA World Cup Brazil: a retrospective survey. $B M J$ Open 2015;5:e007608. doi:10.1136/bmjopen-2015007608

- Prepublication history for this paper is available online. To view these files please visit the journal online (http://dx.doi.org/10.1136/ bmjopen-2015-007608).

Received 7 January 2015 Revised 6 July 2015 Accepted 24 July 2015

\section{CrossMark}

${ }^{1}$ Fédération Internationale de Football Association, Zurich, Switzerland

${ }^{2}$ Department of Sports Medicine, Schulthess Clinic, Zurich, Switzerland ${ }^{3}$ FIFA-Medical Assessment and Research Center (F-MARC), Schulthess Clinic, Zurich, Switzerland

${ }^{4}$ Division of Orthopedics and Trauma Surgery, Geneva University Hospital, Geneva, Switzerland

${ }^{5} \mathrm{MSH}$ Medical School Hamburg, Hamburg,

Germany

${ }^{6}$ Department of Neurology,

Schulthess Clinic, Zurich,

Switzerland

Correspondence to

Dr Martin Vaso;

martin.vaso@fifa.org

\section{ABSTRACT}

Objective: To examine the use of medication of top-level male players during the 2014 FIFA World Cup Brazil.

Design: Retrospective survey.

Participants/information: 736 top level players.

Setting: The teams' physicians disclosed a list of the medications used by each player within $72 \mathrm{~h}$ before each match of the 2014 FIFA World Cup Brazil.

Outcome measures: Average number of medications used per player per match or during the tournament; average number and percentage of players using at least one medication per match or during the tournament.

Results: $67.0 \%$ of all players took various types of medication during the tournament. The most used medications during the tournament were non-steroidal anti-inflammatory drugs (NSAIDs), by $54.2 \%$ of all players, followed by analgaesics (12.6\%); $\beta-2$ agonists were only used by $0.5 \%$. On average, 0.8 medications per player were used before each match. More players were reported taking medications during the knockout round than during the qualification round $(0.36 \pm 0.48$ vs $0.49 \pm 0.50, p<0.001)$. Players from the South American and Asian Confederations took twice as many medications per match as players from the African Confederation $(1.17 \pm 1.55$ and $1.01 \pm 1.26$ vs $0.48 \pm 0.69$, both $p<0.001$ ).

Conclusions: There was high use of NSAIDs during the 2014 FIFA World Cup. Although the intake of NSAIDs per match $(0.35 \pm 0.46$ vs $0.31 \pm 0.48, p<0.01)$ in the 2014 FIFA World Cup decreased compared to the 2010 FIFA World Cup, the average use was still higher than in the 2006 FIFA World Cup, and the average number of all used medications per player remained the same level as 4 years prior, with all its implications for the player's health. More efforts need to be undertaken worldwide in order to reduce the administration of medications in sports, through continuous education for players, starting from a young age, as well as for doctors and paramedics.

\section{INTRODUCTION}

Over the last few years, several studies investigated the use of medication by athletes during

\section{Strengths and limitations of this study}

- The study provides an overview of the medication use of top level players, teams and confederations during the 2014 FIFA World Cup, and shows tendencies in the use of medication by football players since 2002, based on a comparison with reports previously published.

- The information processed is based on information provided by the team physicians; therefore there is no guarantee of complete data.

sports events. ${ }^{1-11}$ These and other studies showed high use of non-steroidal antiinflammatory drugs (NSAIDs) and analgaesics in football as well as in other sports. ${ }^{1-3}$ 5-8 10-17 In international football, specifically, the number of players using NSAIDs per match, as well as the use of $\beta-2$ agonists, increased significantly from the 2006 to the 2010 Fédération Internationale de Football Association (FIFA) World Cup. ${ }^{11}$ Guidelines ${ }^{18-20}$ and scientific papers show potential adverse effects of NSAID use. ${ }^{19}{ }^{21-26}$ This is a reason for concern, as elite athletes were reported to use significantly more medications than agematched controls. ${ }^{27}$ Possible reasons for the high intake of painkillers were for prophylactic pain treatments, as well as for players not yet fully recovered from an injury. ${ }^{2}$

The aim of the present study was to explore the use of medication during the 2014 FIFA World Cup compared to previous FIFA World Cups, ${ }^{6}{ }^{11}$ as several measures had been undertaken since then to reduce the high intake of medication.

\section{METHODS}

Before each match of the 2014 FIFA World Cup, the team physicians were required to share details of all medications taken $72 \mathrm{~h}$ before the match for every nominated player. Team physicians were required to confirm 
that the players had been informed about the processing of the data, that the players voluntarily permitted the release of the data, and that the players released the physician from doctor/patient confidentiality. The methodological scheme used in the present study was the same as reported previously, ${ }^{6}{ }^{11}$ as well as the definition of substance groups: NSAIDs, analgaesics, injected glucocorticosteroids and local anaesthetics, muscle relaxants, respiratory drugs, medication for gastrointestinal and antimicrobial purposes, and against insomnia and anxiety, among others. Paracetamol (acetaminophen) and metamizole were counted as analgaesics and not as NSAIDs. ${ }^{8}$ All supplements declared for a player prior to a match were counted as one independent from the number of subsubstances.

For the 2014 FIFA World Cup, 32 countries ('teams') qualified and nominated 23 players each (total 736 players). Of the 64 matches held (2944 player matches), 48 were in the qualification round and 16 in the knockout round.

\section{Data presentation and statistical analysis}

Data were presented as: (1) average number of medications used per player per match or during the tournament, and (2) average number and percentage of players using at least one medication per match or during the tournament. ${ }^{6} 11$

Analyses included descriptive statistics (frequencies, means, SDs, $95 \% \mathrm{CI}$ ), as well as $\chi^{2}$ tests and tests for comparisons between groups. Significance was considered at $\mathrm{p} \leq 0.05$. CI was used to compare extreme positioned groups with each other. The normality of data distribution was assessed with a skewness below 1 in Excel (based on Pearson's moment coefficient of skewness). Statistical analyses were performed using Excel 2013 and Data Analysis Tool Excel 2013.

\section{RESULTS}

A total of 2346 medications and 930 supplements were reported to be taken by players in the 2014 FIFA World Cup. NSAIDs were the medications most taken $(43.9 \%$; $\mathrm{n}=1030$ ), and diclofenac was the NSAID most taken (59.3\% of the NSAIDs; $n=611$ ) followed by cyclooxygenase (COX)-II-inhibitors (16.4\% of the NSAIDs; $n=169)$. Other pain-related medication groups reported were 'other analgaesics' (7.7\%; n=181), 'local anaesthetic injections' (2.6\%; $\mathrm{n}=62)$ and 'muscle relaxants' (2.4\%; $\mathrm{n}=57)$. Glucocorticosteroid injections were $3.1 \% \quad(\mathrm{n}=72)$, $\beta-2$ agonists $1.2 \% \quad(n=27)$, medications against insomnia and anxiety $6.1 \% \quad(\mathrm{n}=142)$, respiratory medications (without antihistaminic and $\beta-2$ agonists) $4.1 \% \quad(\mathrm{n}=97)$ and antimicrobial agents $4.6 \% \quad(\mathrm{n}=107)$ of all medications prescribed at least $72 \mathrm{~h}$ prior to a match. The most used $\beta-2$ agonists were salbutamol $(n=17)$ followed by salmeterol $(n=8)$ and formoterol $(n=2)$.

On average, $67 \%$ of the players took at least one type of medication during the tournament, and $39.7 \%$ of the players did so before each match (see table 1). The team with the lowest percentage of players taking a medication during the tournament had an average of $22 \%$ of the players taking a medication, repetitively. The most frequently prescribed medications were NSAIDs.

The average number of different medications declared was 0.80 per player per match and 1.67 per player during the tournament. Substantial differences between the teams were found: in one team, each player took medications during the tournament, with an average of 4.70 different medications per player. The maximum average number of prescribed medications found in all teams was 5.0 medications per player, the minimum was 0.30 medications per player in a team during the tournament. The average number of medications per player and per match ranged from 0.11 to 1.93 , while NSAID intake varied from 0.04 to 1.02 NSAIDs per player and per match. Two players took the reported maximum of nine medications in the $72 \mathrm{~h}$ prior to a match.

In the qualification round, fewer players took at least one medication per match than in the knockout round (see table 1). A similar increase from the qualification to the knockout round was found for the mean number of all medications per player and per match (see table 1, $\mathrm{p}<0.01)$, the mean number of NSAIDs per player and per match $(0.33 ; 95 \%$ CI 0.31 to 0.35 vs $0.40 ; 95 \%$ CI 0.36 to 0.44$)$, and the average number of 'other' medications $(0.28 ; 95 \%$ CI 0.25 to 0.31 vs $0.40 ; 95 \%$ CI 0.34 to $0.46)$.

Significantly more players from the South American and Asian Confederations took medications than those from the African and European Confederations (see table 1 , both $\mathrm{p}<0.001$ ).

The average number of medications taken was higher in players born between 1976 and 1981 ( $\mathrm{n}=72$; 1.97; 95\% CI 1.5 to 2.44 ), compared to younger players born between 1982 and $1990(\mathrm{n}=541 ; 1.70 ; 95 \%$ CI 1.54 to 1.86), and between 1991 and $1996(\mathrm{n}=122 ; 1.38 ; 95 \%$ CI 1.13 to 1.63$)$. We compared the players born in the six oldest and six most recent years, and did not include one player, born in 1971, in this analysis, as he was an outlier.

\section{DISCUSSION}

In the 2014 FIFA World Cup, the average number of medications taken per match decreased for NSAIDs $(-11.6 \%)$, analgaesics $(-15.3 \%), \beta-2$ agonists $(-67.2 \%)$ and supplements $(-8.7 \%)$, and increased for antihistamines $(+9.4 \%)$ and injections $(+7.3 \%)$, compared to the 2010 FIFA World Cup. Compared to the 2006 FIFA World Cup, the use of NSAIDs $(+5 \%)$ and analgaesics $(+48 \%)$ per match increased, the same number of injections were given, and antihistamines (-34\%), $\beta-2$ agonists $(-39 \%)$ and supplements $(-11 \%)$ decreased (see figure 1$)$.

The decrease in the use of NSAIDs from the 2010 to the 2014 FIFA World Cup is in line with other recent studies. ${ }^{1}{ }^{15}$ However, the use of NSAIDs per match 
Table 1 Use of medication in the 2014 FIFA World Cup

\begin{tabular}{|c|c|c|c|c|c|}
\hline & \multirow[b]{2}{*}{$\begin{array}{l}\text { Total number } \\
\text { of medications }\end{array}$} & \multicolumn{2}{|c|}{$\begin{array}{l}\text { Average number of } \\
\text { medications used per player } \\
\text { (mean } \pm \text { SD) }\end{array}$} & \multicolumn{2}{|c|}{$\begin{array}{l}\text { Percentage of players using a } \\
\text { medication }\end{array}$} \\
\hline & & Per match & $\begin{array}{l}2014 \text { FIFA } \\
\text { World Cup }\end{array}$ & Per match (\%) & $\begin{array}{l}2014 \text { FIFA } \\
\text { World Cup (\%) }\end{array}$ \\
\hline Any medication & 2346 & $0.80 \pm 1.17$ & $1.67 \pm 1.85$ & 39.7 & 67.0 \\
\hline NSAIDs & 1030 & $0.35 \pm 0.58$ & $0.72 \pm 0.88$ & 30.6 & 54.2 \\
\hline Injections ${ }^{\star}$ & 134 & $0.05 \pm 0.26$ & $0.09 \pm 0.39$ & 3.5 & 6.1 \\
\hline Analgaesics & 181 & $0.06 \pm 0.27$ & $0.14 \pm 0.39$ & 5.4 & 12.6 \\
\hline$\beta-2$ agonists & 27 & $0.01 \pm 0.12$ & $0.01 \pm 0.12$ & 0.6 & 0.5 \\
\hline Antihistamines & 72 & $0.02 \pm 0.16$ & $0.07 \pm 0.28$ & 2.4 & 6.3 \\
\hline Others & 902 & $0.31 \pm 0.68$ & $0.65 \pm 1.04$ & 22.0 & 38.7 \\
\hline \multicolumn{6}{|l|}{ By round } \\
\hline Qualifier & 1635 & $0.74 \pm 1.1$ & & 36.6 & \\
\hline Final & 711 & $0.97 \pm 1.34$ & & 48.8 & \\
\hline \multicolumn{6}{|l|}{ By confederation } \\
\hline AFC & 277 & $1.01 \pm 1.26$ & $1.46 \pm 0.86$ & 53.3 & 65.2 \\
\hline CAF & 187 & $0.48 \pm 0.69$ & $1.16 \pm 0.58$ & 38.6 & 61.7 \\
\hline UEFA & 775 & $0.64 \pm 0.96$ & $1.44 \pm 1.28$ & 40.1 & 61.5 \\
\hline CONMEBOL & 808 & $1.17 \pm 1.55$ & $2.67 \pm 1.62$ & 54.6 & 81.2 \\
\hline CONCACAF & 299 & $0.81 \pm 1.1$ & $1.16 \pm 0.58$ & 45.4 & 73.9 \\
\hline
\end{tabular}

during the 2014 FIFA World Cup was higher than during the 2006 FIFA World Cup, and therefore still on a high level (figure 1$).^{6}$ This is a cause for concern since athletes tend to take more than the recommended dose for analgaesic medications, ${ }^{14}$ although it is known that the risk of adverse effects increases significantly with increasing analgaesic dose. ${ }^{23} 28$ Serious adverse effects of NSAIDs, such as gastrointestinal ${ }^{9}$ 21-23 2930 and cardiovascular related events, ${ }^{23}{ }^{31}$ as well as a delay of musculoskeletal tissue healing ${ }^{19} \quad 21 \quad 32$ and renal issues $^{21}{ }^{23}$ have been reported. However, the short-term use of NSAIDs seems to have a positive effect regarding soft tissue ${ }^{33}$ while the long-term outcome seems to be negative. ${ }^{34} 35$ The use of NSAIDs for prophylactic purposes seems to be common in football and other sports $^{1620} 2136$ despite its known adverse effects. There are even indications that NSAIDs do not prevent pain when taken for prophylactic purposes. ${ }^{23}$

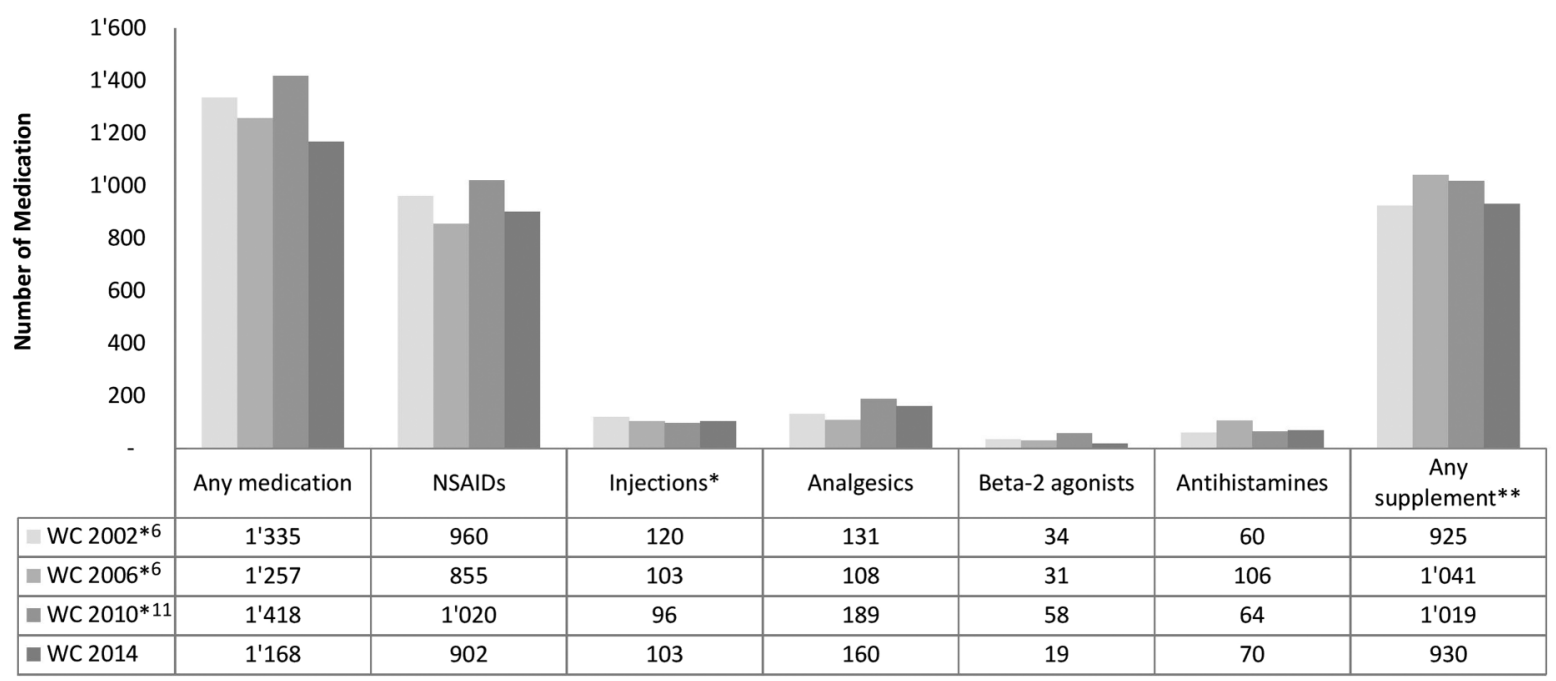

*Corticosteroid and local anaesthetic injection only ${ }^{0.11}$

**Declared supplements per player per match counted as one supplement independent from the sub-substances

NSAID: non-steroidal anti-inflammatory drugs.

Figure 1 Development of use of a substance per match per player in FIFA World Cups from 2002 to 2006, 2010 and 2014. 
There was a decrease $(67.2 \%)$ of $\beta-2$ agonist use during the 2014 FIFA World Cup $(n=4)$ compared to the 2010 FIFA World Cup $(\mathrm{n}=20)$, the lowest value since the 2002 FIFA World Cup. The use of $\beta-2$ agonist increased from 2006 to 2010 but was still low compared to other sports (such as cycling or as the overall average intake in the Summer Olympics). ${ }^{6} 1011$ From 2008 to 2010, medication requests submitted to the Portuguese Anti-Doping Authority showed a decrease of applications for inhalers by approximately half. ${ }^{37}$ The reason was seen as objective asthma testing becoming mandatory, and the influence of changing World Anti-Doping Agency (WADA) regulations for the intake of $\beta-2$ agonists. ${ }^{37}$ In 2012, WADA removed formoterol (only when taken by inhalation at therapeutic dosages) from 'section $3 \beta-2$ agonists' of the prohibited list. All $\beta-2$ agonists reported during the 2014 FIFA World Cup were exceptions from the WADA prohibited list where there was no necessity to request a therapeutic use exemption (TUE) as long as certain maximum values would not be exceeded. However, all $\beta-2$ agonists were administered to only four players during the tournament. The decrease of reported $\beta-2$ agonist use in the 2014 FIFA World Cup might be due to the system change of the WADA regulations. Further investigations might be required to evaluate such a correlation.

Although the use of injections, most common local anaesthetics, glucocorticosteroids and antihistamines increased in the 2014 FIFA World Cup compared to the 2010 FIFA World Cup, the values were the same (injections) or lower (antihistamines) than the reported values from the 2006 FIFA World Cup. Concerning injections during the 2014 FIFA World Cup, fewer players were given more injections compared to the 2010 FIFA World Cup. This might be an indication that fewer players were suffering from local inflammation and pain, or that certain teams were more restrictive with the use of injections than others.

An intriguing finding was that the use of platelet rich plasma (PRP) was reported in four players, though the administration is meant to be for long-term treatment and not as short-term use before a match. PRP treatment ${ }^{38}$ is controversially discussed in the literature but is not featured on the WADA prohibited list.

The intake of supplements could only be compared with the results of previous FIFA World Cups concerning the use of supplements per player and per match due to a different counting. Findings in the literature are contradictory. In football, while the use of supplements increased from the 2002 to 2006 FIFA World Cups, it decreased from the 2006 to 2010 events. ${ }^{6} 11$ The decrease of supplement intake continued from 2010 to 2014 (figure 1). In the Olympics, the reported use of (dietary) supplements decreased from 2002 to 2009. ${ }^{39}$ The reason might be that athletes do not report all the supplements they are taking to their team physician, or it may reflect better education regarding supplement taking. Another reason might be better knowledge of the risk of possible contamination of supplements. However, compared to endurance sports, the use of supplements in team sports seems to be lower in general. ${ }^{39}$

As an already known pattern from previous studies, ${ }^{6} 11$ in the 2014 FIFA World Cup, the administration of NSAIDs has a wide spread as well, depending on the country/confederation the athletes are playing for, or because of the team/national team physician. There is also a wide spread in the use of medication, depending on the team and continent the player plays for. Players from the South American and Asian Confederations took more medications per match than players from the African and European Confederations. Concerning African athletes, results showing a lower intake of medication are in accordance with previous findings in Track and Field, whereas the results showing a higher intake of medication by players from the Asian Confederation are contradictory to those findings. ${ }^{8}$ This could be due to different cultural approaches to medications, or a reporting bias of the team physician. Another factor might be that players often do not play in the country of their national team during the regular season, which could have an impact on their medication intake.

There is a trend of higher medication intake in older players compared to younger players. The reason might be more willingness of a player to consume medications at the end of a career, or a stronger need to cure symptoms at an older age. However, this finding needs further studies to investigate the reason.

WADA describes all prohibited substances and methods in sport in its prohibited list. From all reported medications in the 2014 FIFA World Cup, only a very small amount were from the prohibited list, and therefore had to be approved in advance to be given a TUE due to a medical necessity. In the view of doping, all other medications were permitted to be used. ${ }^{40}$

\section{Limitations}

For one match, an empty medication list was submitted. This report is most likely incorrect since the team physician previously submitted medication lists with several medications. Further, the single dose of medications used, as well as the possibility that medications taken by players was not declared by them to their team doctors, were not considered in this study.

\section{CONCLUSIONS}

The use of medication during the 2014 FIFA World Cup was on the same level as during the 2010 FIFA World Cup, the use of NSAIDs decreased but remained on a high level. Also, even more injections were administered. In some of the participating teams, a critical and questionable amount of different medications used were seen.

Taking all evaluated data into account, there is no reversal of the trend of high amounts of medications consumed. The team physicians must be more conscious 
of their responsibility to the players, and the players should be taught to be more critical concerning the use of medications. Unfortunately, the previously presented facts have not changed the attitudes of the players and medical staff to use fewer medications during the FIFA World Cups. More effort from all involved parties is required to reduce the consumption of medication in football.

Acknowledgements The authors gratefully acknowledge FIFA (Fédération Internationale de Football Association) for funding this study, as well as all team physicians for their collaboration (R Karabeg, J Runco, A Picantco, S Boubakary, W Ngatchou, G Carcuro, C Castro, A Elizondo, C Dah, C Eirale, Z Bahtijarevic, P Maldonado, I Beasley, F Le Gall, Prof T Meyer, A Matuawakilu, C Christopoulos, R Perez, J Zeron, P Khanlari, E Castellacci, L Gatteschi, H Ikeda, K Shimada, J Seob, J Vázquez, E Goedhard, I Gyaran, J Jones, E Bezuglov, 0 Celada, R Grossen, C Wetzel, E Barbosa and G Chiampas). The authors express gratitude to the members of the FIFA Sports Medical Committee, chairman M D'Hooghe, deputy chairman K Chung, A Zerguini, Prof R Madero, Prof L Peterson, T Babwah, G Singh, H A Ahmed, A Edwards, B Mandelbaum, C Palavicini, J Chomiak, M Al Maadheed, E Hermann, M Dohi and J Sekajugo, for obtaining the data.

Contributors MV was the lead investigator. All the authors were involved in the study design and reviewed the draft of this report. MV, AW and JD coordinated the data management, and MV drafted this report. AW carried out the statistical analysis, reviewed by PMT and AJ. JD was the 2nd lead investigator.

Funding Fédération Internationale de Football Association, Zurich, Switzerland-MV, JD, AJ and AW were funded by FIFA.

Competing interests None declared.

Ethics approval The protocol was approved by an Institutional Review Board (Kantonale Ethikkomission, EK 12/2007) in Zurich, Switzerland.

Provenance and peer review Not commissioned; externally peer reviewed.

Data sharing statement No additional data are available.

Open Access This is an Open Access article distributed in accordance with the Creative Commons Attribution Non Commercial (CC BY-NC 4.0) license, which permits others to distribute, remix, adapt, build upon this work noncommercially, and license their derivative works on different terms, provided the original work is properly cited and the use is non-commercial. See: http:// creativecommons.org/licenses/by-nc/4.0/

\section{REFERENCES}

1. Earl M, Vouillamoz M, Kwiatkowska D, et al. The uefa euro 2012 anti-doping programme-scientific review. Biol Sport 2014;31:85-93.

2. Tscholl P, Feddermann N, Junge A, et al. The use and abuse of painkillers in international soccer: data from 6 FIFA tournaments for female and youth players. Am J Sports Med 2009;37:260-5.

3. Taioli E. Use of permitted drugs in Italian professional soccer players. Br J Sports Med 2007;41:439-41.

4. Tsitsimpikou C, Tsiokanos A, Tsarouhas K, et al. Medication use by athletes at the Athens 2004 Summer Olympic Games. Clin J Sport Med 2009;19:33-8.

5. Corrigan B, Kazlauskas R. Medication use in athletes selected for doping control at the Sydney Olympics (2000). Clin J Sport Med 2003;13:33-40.

6. Tscholl $P$, Junge A, Dvorak J. The use of medication and nutritional supplements during FIFA World Cups 2002 and 2006. Br J Sports Med 2008;42:725-30.

7. Huang SH, Johnson K, Pipe AL. The use of dietary supplements and medications by Canadian athletes at the Atlanta and Sydney Olympic Games. Clin J Sport Med 2006;16:27-33.

8. Tscholl $\mathrm{P}$, Alonso JM, Dollé G, et al. The use of drugs and nutritional supplements in top-level track and field athletes. Am J Sports Med 2010;38:133-40.

9. Alaranta A, Alaranta $\mathrm{H}$, Heliövaara $\mathrm{M}$, et al. Ample use of physician-prescribed medications in Finnish elite athletes. Int $J$ Sports Med 2006;27:919-25.
10. Thuyne WV, Delbeke FT. Declared use of medication in sports. Clin J Sport Med 2008;18:143-7.

11. Tscholl PM, Dvorak J. Abuse of medication during international football competition in 2010-lesson not learned. Br J Sports Med 2012;46:1140-1.

12. Gorski T, Cadore EL, Pinto SS, et al. Use of NSAIDs in triathletes: prevalence, level of awareness and reasons for use. $\mathrm{Br} J$ Sports Med 2011;45:85-90.

13. Da Silva ER, De Rose EH, Ribeiro JP, et al. Non-steroidal anti-inflammatory use in the XV Pan-American Games (2007). Br J Sports Med 2011;45:91-4.

14. Wolf DA, Miller TW, Pescatello LS, et al. National collegiate athletic association division I athletes' use of nonprescription medication. Sports Health 2011;3:25-8.

15. Stache S, Close JD, Mehallo C, et al. Nonprescription pain medication use in collegiate athletes: a comparison of samples. Phys Sportsmed 2014;42:19-26.

16. Joslin J, Lloyd JB, Kotlyar T, et al. NSAID and other analgesic use by endurance runners during training, competition and recovery. $S$ Afr J Sports Med 2013;25:101-4.

17. Kavukcu E, Burgazlı KM. Preventive Health Perspective in Sports Medicine: The Trend at the Use of Medications and Nutritional Supplements during 5 Years Period between 2003 and 2008 in Football. Balkan Med J 2013;30:74-9.

18. Paoloni JA, Milne C, Orchard J, et al. Non-steroidal anti-inflammatory drugs in sports medicine: guidelines for practical but sensible use. Br J Sports Med 2009;43:863-5.

19. Ziltener JL, Leal S, Fournier PE. Non-steroidal anti-inflammatory drugs for athletes: an update. Ann Phys Rehabil Med 2010;53:278-82, 282-8.

20. Warden SJ. Prophylactic misuse and recommended use of non-steroidal anti-inflammatory drugs by athletes. Br J Sports Med 2009;43:548-9

21. Warden SJ. Prophylactic use of NSAIDs by athletes: a risk/benefit assessment. Phys Sportsmed 2010;38:132-8.

22. Van Wijck K, Lenaerts K, Van Bijnen AA, et al. Aggravation of exercise-induced intestinal injury by lbuprofen in athletes. Med $\mathrm{Sci}$ Sports Exerc 2012;44:2257-62.

23. Küster M, Renner B, Oppel $\mathrm{P}$, et al. Consumption of analgesics before a marathon and the incidence of cardiovascular, gastrointestinal and renal problems: a cohort study. BMJ Open 2013;3:pii: e002090.

24. Vuolteenaho K, Moilanen T, Moilanen E. Non-steroidal anti-inflammatory drugs, cyclooxygenase-2 and the bone healing process. Basic Clin Pharmacol Toxicol 2008;102:10-14.

25. Wheeler P, Batt ME. Do non-steroidal anti-inflammatory drugs adversely affect stress fracture healing? A short review. $\mathrm{Br} J$ Sports Med 2005;39:65-9.

26. Virchenko O, Skoglund B, Aspenberg P. Parecoxib impairs early tendon repair but improves later remodeling. Am J Sports Med 2004;32:1743-7.

27. Alaranta A, Alaranta $\mathrm{H}$, Helenius I. Use of prescription drugs in athletes. Sports Med 2008;38:449-63.

28. Castellsague J, Riera-Guardia N, Calingaert B, et al. Individual NSAIDs and upper gastrointestinal complications: a systematic review and meta-analysis of observational studies (the SOS project). Drug Saf 2012;35:1127-46.

29. Massó González EL, Patrignani P, Tacconelli S, et al. Variability among nonsteroidal antiinflammatory drugs in risk of upper gastrointestinal bleeding. Arthritis Rheum 2010;62:1592-601.

30. Bhala N, Emberson J, Merhi A, et al. Vascular and upper gastrointestinal effects of non-steroidal anti-inflammatory drugs: meta-analyses of individual participant data from randomised trials. Lancet 2013;382:769-79.

31. McGettigan P, Henry D. Cardiovascular risk with non-steroidal anti-inflammatory drugs: systematic review of population-based controlled observational studies. PLoS Med 2011;8:e1001098.

32. Slatyer MA, Hensley MJ, Lopert R. A randomized controlled trial of piroxicam in the management of acute ankle sprain in Australian Regular Army recruits. The Kapooka Ankle Sprain Study. Am J Sports Med 1997;25:544-53.

33. Chen MR, Dragoo JL. The effect of nonsteroidal anti-inflammatory drugs on tissue healing. Knee Surg Sports Traumatol Arthrosc 2013;21:540-9.

34. Mackey AL, Mikkelsen UR, Magnusson SP, et al. Rehabilitation of muscle after injury-the role of anti-inflammatory drugs. Scand $J$ Med Sci Sports 2012;22:e8-14.

35. Schoenfeld BJ. The use of nonsteroidal anti-inflammatory drugs for exercise-induced muscle damage: implications for skeletal muscle development. Sports Med 2012;42:1017-28.

36. Holmes N, Cronholm PF, Duffy AJ, et al. Nonsteroidal antiinflammatory drug use in collegiate football players. Clin J Sport Med 2013;23:283-6. 
37. Couto $M$, Horta L, Delgado L, et al. Impact of changes in anti-doping regulations (WADA Guidelines) on asthma care in athletes. Clin J Sport Med 2013;23:74-6.

38. Engebretsen L, Steffen K, Alsousou J, et al. IOC consensus pape on the use of platelet-rich plasma in sports medicine. Br J Sports Med 2010;44:1072-81.
39. Heikkinen A, Alaranta A, Helenius I, et al. Use of dietary supplements in Olympic athletes is decreasing: a follow-up study between 2002 and 2009. J Int Soc Sports Nutr 2011;8:1.

40. (Unattributed): Citing sources: https://www.wada-ama.org/en/ what-we-do/prohibited-list: 5 December 2014. 